\title{
THE INFLUENCING FACTORS OF ARCHITECTURAL COMPOSITION AND THE ARRANGEMENT OF HUMAN SETTLEMENT IN ORCHID ISLAND
}

\author{
C.-J. CHEN ${ }^{1} \&$ S.-T. KUO ${ }^{2}$ \\ ${ }^{1}$ Department of Creative Design and Architecture, National University of Kaohsiung, Taiwan. \\ ${ }^{2}$ Department of Urban Planning, National Cheng Kung University, Taiwan.
}

\begin{abstract}
This paper analyzes the vernacular architecture and human settlement of Orchid Island. It attempts to explore the influencing factors of architectural composition and the arrangement of villages regarding their environmental conditions. Orchid Island is mostly populated by an aboriginal people called the Tao. Six tribes totaling 3000 people live on the island, coexisting among different cultures and traditions. The subterranean clustered buildings are the most particular configuration of the island. These constructs demonstrate a conspicuous vernacular figure, reflecting a high level of efficiency and practicality, which corresponds with the local environment and the landscape of the island. Although the settlement space and the island's land use change gradually due to various socio-economic factors, the traditional subterranean buildings survive; they are conserved and used primarily by two tribes called the Langdau and Yehyin. Although both tribes reside on this small island, some distinct physical differences in the buildings they use can be recognized. The goal of this research is to explore the influencing factors by comparing representative examples from each tribe. The study of the research consists of (i) a field investigation on the configuration of buildings and the physical difference between two tribes and (ii) a correlation analysis on the settlement arrangement and the composition of traditional buildings with their environmental conditions. This research presents the dominated influencing factors of buildings and the arrangement of human settlement of the island. The obvious differences between the two tribes can be specified in accordance with the geological and climatic conditions.
\end{abstract}

Keywords: Influencing factors, Orchid Island, subterranean building.

\section{INTRODUCTION}

Orchid Island (called Lan-Yu in Mandarin) is off Taiwan's southeast coast. Six tribes consisting of 3000 people inhabit the island in a primitive, but sustainable way; they exhibit a unique human settlement, domestic culture, and societal system, which differ greatly from the other peoples of the main Taiwan Island. Orchid Island is a volcanic island formed by magma that erupted from the ocean floor. It used to be called 'Redhead Island' because the peaks of the mountains at the northwest corner resemble red human heads in the crimson rays of the setting sun. The name 'Orchid Island' refers to the many wild orchids that once grew in the humid and rainy climate. The diverse ecosystems and the unique cultures are the alluring and distinctive characteristics of this island.

\section{DESCRIPTION OF HUMAN SETTLEMENTS}

Orchid Island consists of six villages that are distributed around the coast of the island: Yayu (Yeyou), Iraralay (Langdau), Iranumilk (Dongqing), Ivarinu (Yeyin), Imourud (Hongtou), and Iratai (Yuren) (see Fig. 1). The villages are situated near the port and are ringed by a paddy field where taro is the primary crop for the Tao people. The buffer zone between the seashore serves as the shipyard, cemetery, and desolate area. Behind the villages, mountains and a forest exist, which provide a rich water resource and construction materials, respectively (see Fig. 2).

The Tao people have depended primarily on the sea for their livelihood, a fact which is reflected in their unique culture. The men wear narrow loincloths for convenience when fishing or hunting; they use richly decorated canoes, similar to what other Austronesian people use. Behind the 


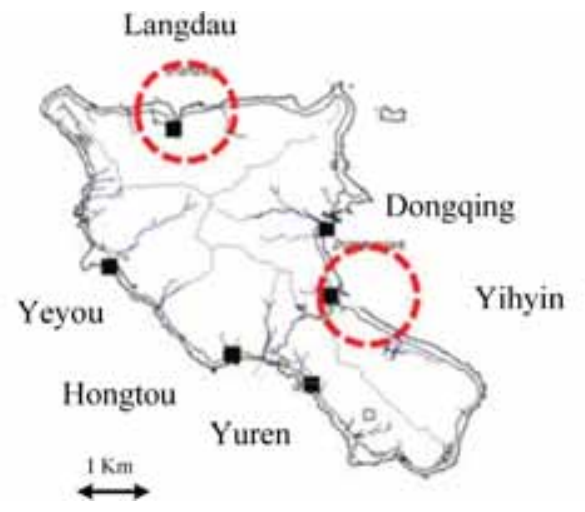

Figure 1: The Orchid Island [2].

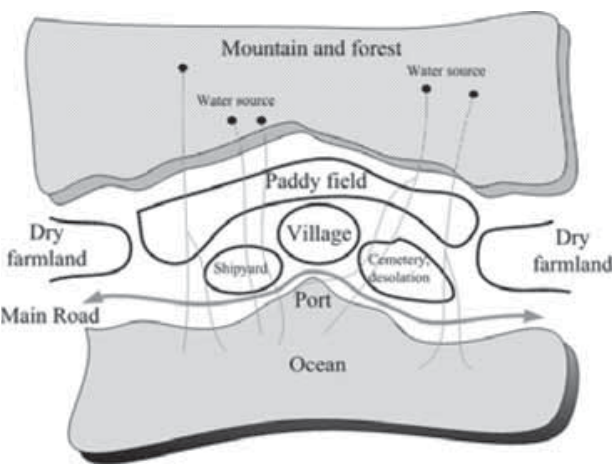

Figure 2: The composition of human settlements [1].

construction of this well-crafted canoe are the symbols of social organization and the inheritance of the traditional culture that hold together the consciousness of the Tao people.

3 VERNACULAR ARCHITECTURE

The original Taos' dwellings were built partially underground and were considered 'comprehensive' in design. A 'complete' traditional dwelling consists of three elements that serve as inclusive living units: a working house, a resting platform, and a subterranean main house (see Figs 3 and 4). The main house is dug into the earth as a spacious pit, so that the roof is nearly level with the surface of the surrounding earth. The boundary between houses is walled by cobbles to resemble a natural flow. The efficient drainage system features high permeability and rarely causes flooding in the village. For Tao people, the subterranean house not only shelters their families against natural disasters, especially typhoons and torrid heat during the summer, but also symbolizes the vital tradition and social status of adult males in the tribe. The various sizes of dwellings in the village signify the evolution of family life in addition to the practical changes of functional needs [1].

\subsection{The composition of dwellings}

Figure 5 shows a complete dwelling unit formed by three elements for the Tao people. The subterranean main house is situated in the middle of the site, featuring a lower ground level than the 


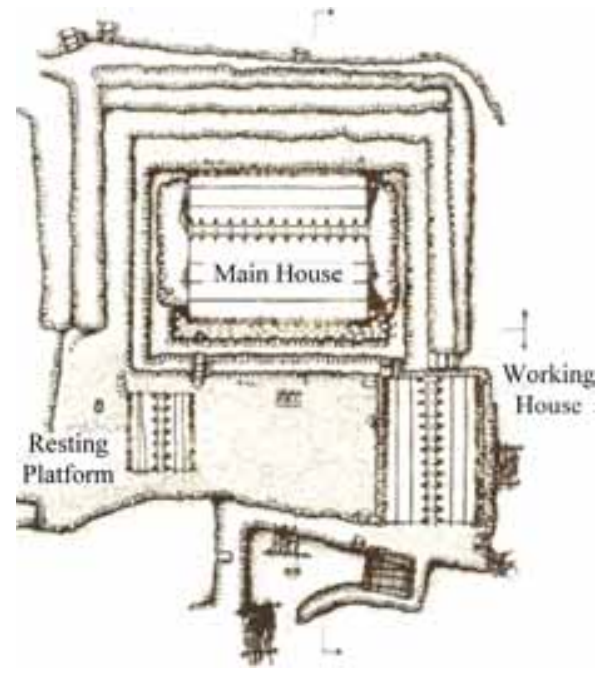

Figure 3: The arrangement of a living unit.

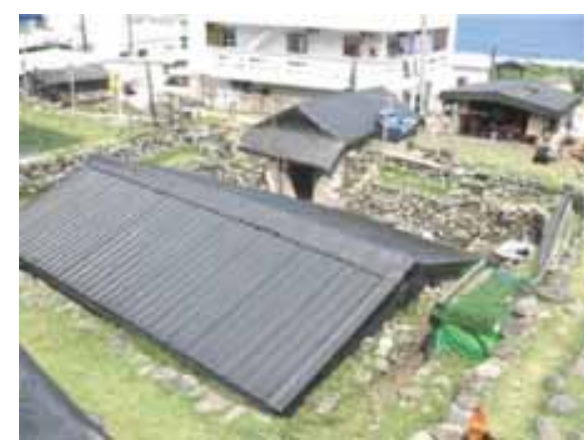

Figure 4: The three elements of a dwelling.

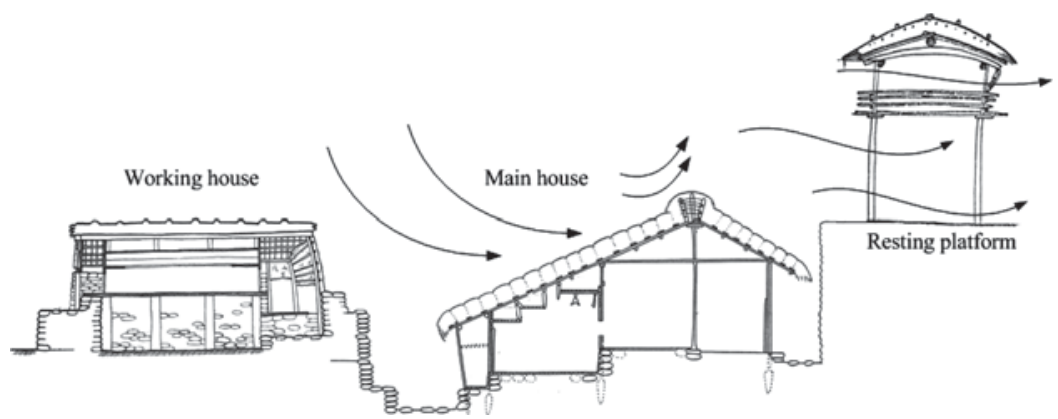

Figure 5: The three elements of a traditional dwelling. 

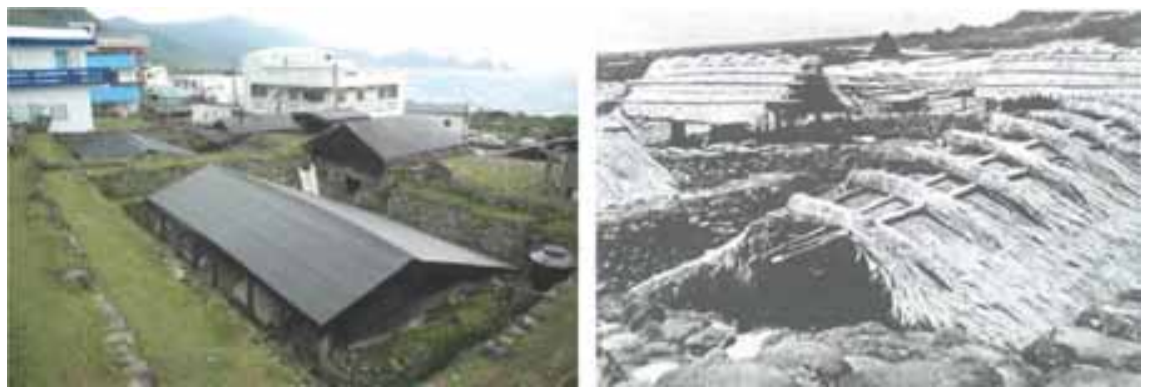

Figure 6: The restored dwelling in 2008 (left-hand side) and old dwelling in 1920 (right-hand side).

other buildings. The sizes of such a main house symbolize the social status, human maturity, and construction capacity of the owner. The working house (Magaran) signifies a temporary and functional space for young people. It serves as an accommodation and working space when young people become independent, but yet still unable to build a main house. The elevated resting platform provides mainly a communication and relaxing space. In general, all buildings are placed facing the sea and are distributed along the contour of the inclined land. Although modern materials and techniques are integrated in local construction more and more, the traditional components of a dwelling remain intact. Figure 6 shows a significant difference in the roof material used in actual houses and historical houses.

\subsection{The eco-design and social meaning}

On the one hand, the meanings of traditional dwellings are a good correlation with the environmental conditions; on the other hand, it is the reflection of the family chronicle in space. The subterranean main houses provide an ideal shelter against typhoons, which are the most destructive disaster to affect the island. Although the buildings are constructed under ground level within a pit, the efficient drainage can always prevent the problem of flooding (Fig. 7).

In accordance with the traditional process of construction, the pit for the main house should be observed and evaluated for several years to assure perfect drainage (Fig. 8). The different depths of pits are thus defined by considering this practical function and geological condition. At the same time, for the Tao people, main houses signify the maturity and the riches of a family. The number of entrance doors is proportional to the economic capacity and social status of the family. Most main buildings have three or four entrance doors.

All families maintain working houses (Fig. 9), which represent a transitional type of building. When the young commence their independence, these semi-subterranean piloti houses support their simple living needs before they construct their main house. The working house is also a place for working during the day. It may also be used for storage. The resting platforms are usually built on the highest place in the village. This pavilion-like structure consists of a wooden post-beam and thatch roof. It not only serves as a space for people to cool off and relax but also serves as an important social area for both family and guests. There are no standard height and form specifications for the resting platform. In addition, this platform functions as an observation point to look out over the village, and it is considered an ideal place for napping in the hot summer. Different forms of resting platforms are shown in Figs 10 and 11 [4]. 


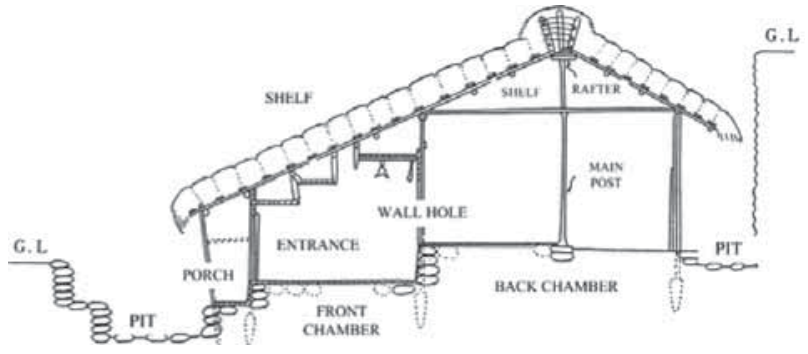

Figure 7: The profile of a main house [3].
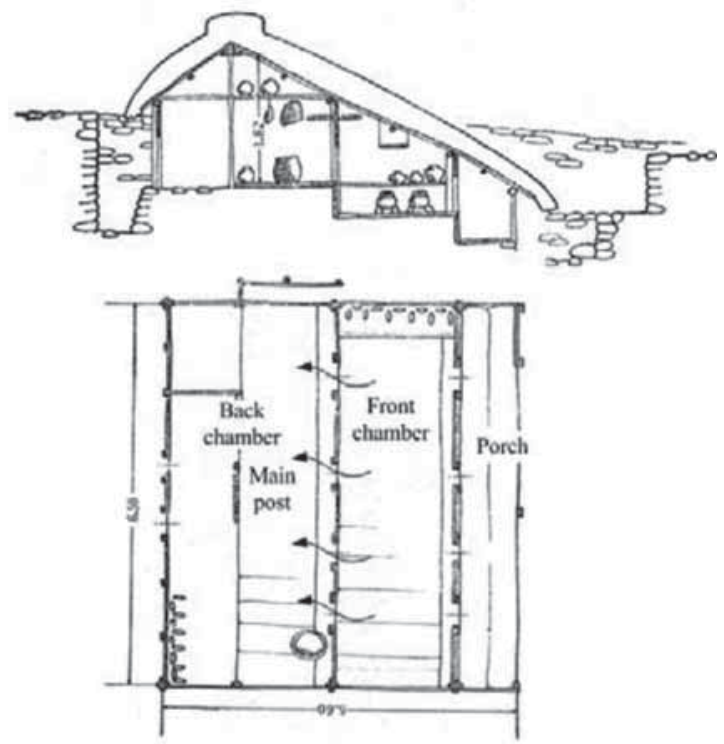

Figure 8: The arrangement of a main house [3].

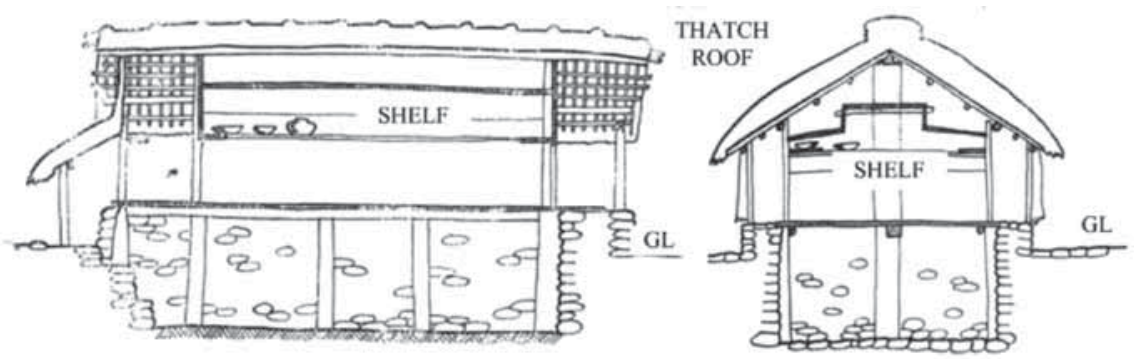

Figure 9: The working house [3]. 


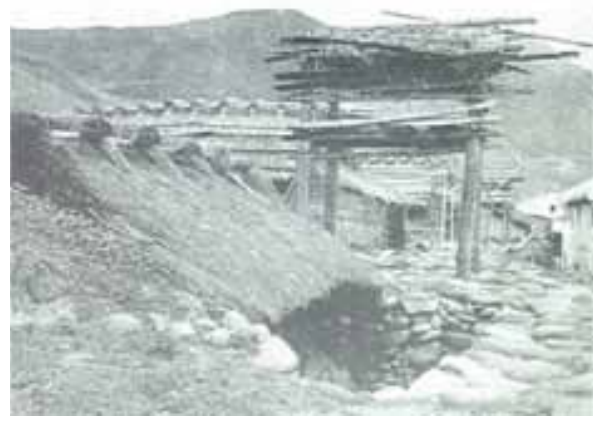

Figure 10: The resting platform in 1930 [4].

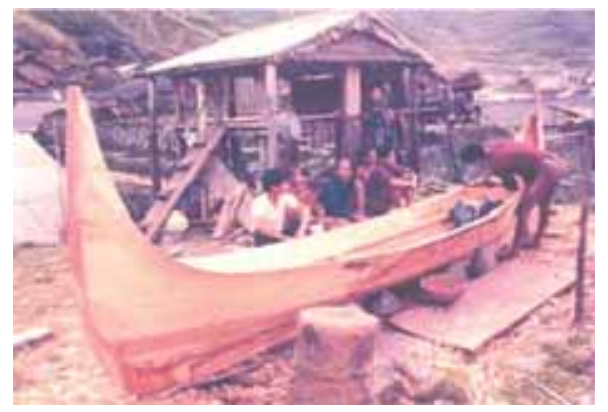

Figure 11: The resting platform in 1960 [4].

\section{A COMPARATIVE STUDY}

Two villages, Yehyin and Langdau, were selected as study cases due to their originality and intact integrity of their settlements. This study focuses on the comparison of settlement arrangement as well as several details of traditional dwellings. The core purpose of this study is to identify a rational explanation for how vernacular conditions or constraints can influence the formation of building types as well as village arrangements.

\subsection{Settlement comparison}

Situated on the eastern side of the island, the Yehyin village began to extend its living territory in 1960, instead of demolishing the original site. The new site is located parallel to the original old village. Almost every family kept their own traditional dwelling or at least the land inherited from their ancestors (see Figs 12 and 13). Neither landscape nor traditional dwelling is rudely changed by the modern policy of land use. Figure 13 shows the traditional dwellings adjoining new buildings in Yehyin. The Langdau village is located on the northern side of the island. Due to its limited territory, the village has had to gradually transform its building type and overall landscape. In addition, the village extended its new quarter in the direction of the mountains. The old part of the village thus shows a typical transitional appearance.

Risks of such developments include the weakening of the traditional organization of the human settlement and the interruption of the traditional living culture. Figures 14 and 15 show the original village located on a narrow site between the seashore and the mountains. 


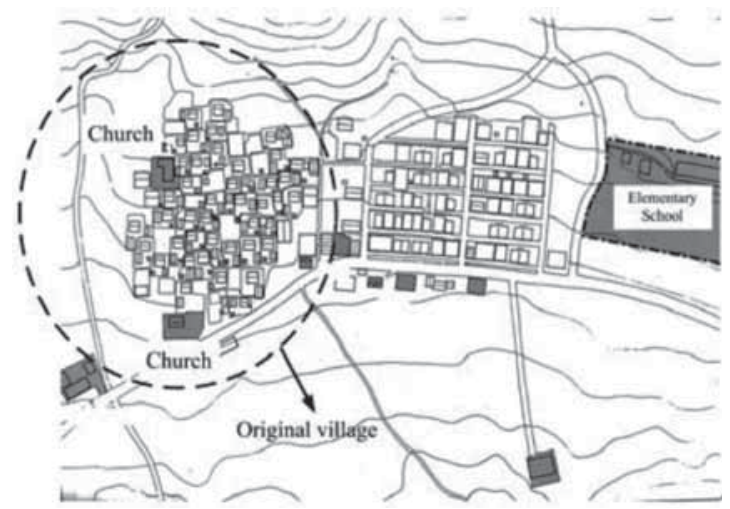

Figure 12: The Yehyin village (left-hand side) [5].

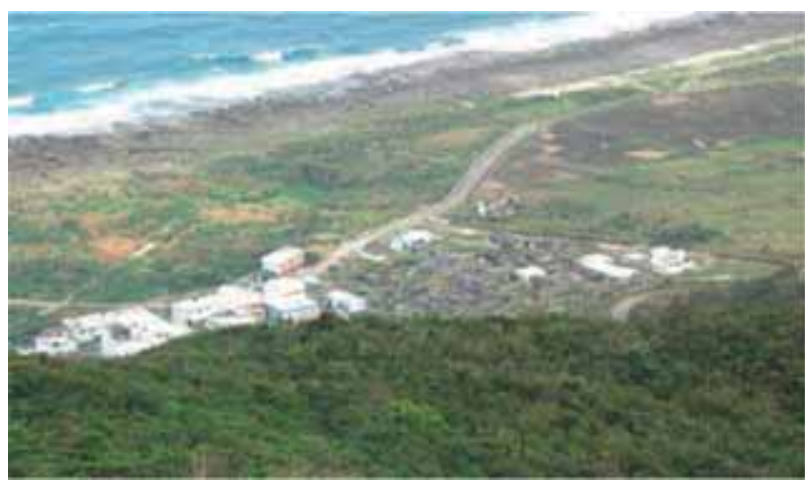

Figure 13: The original village is on the left-hand side of the new village (right-hand side).

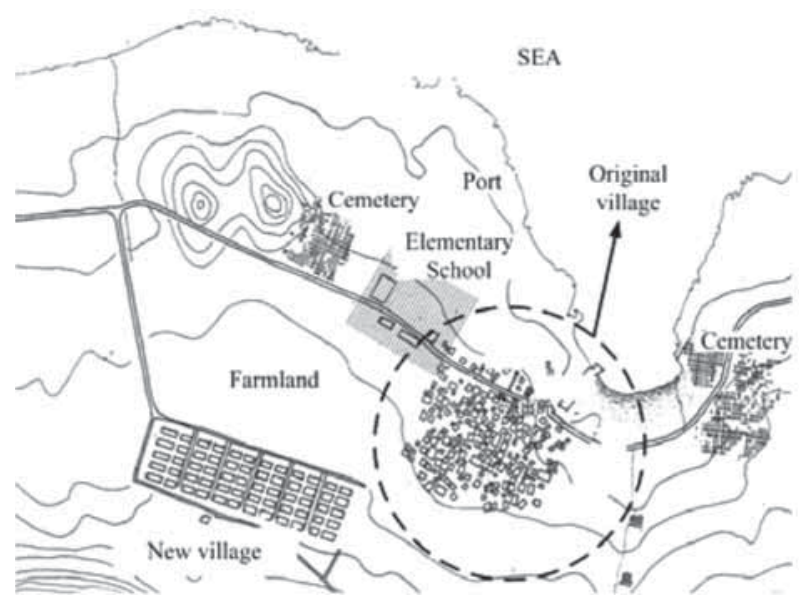

Figure 14: The configuration of Langdau village [5]. 


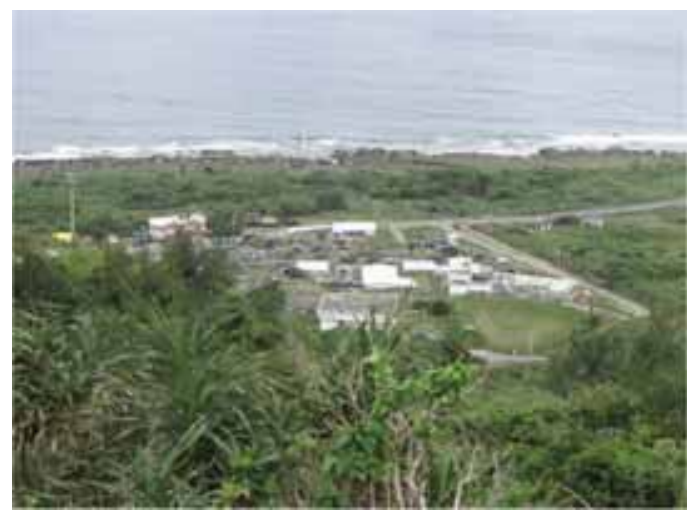

Figure 15: The Langdau village.

The common principles of the arrangement of both villages are (i) the original villages consist of traditional dwellings that are randomly dispersed but respond well to their environmental, geological, and topographical conditions and (ii) a gradual transformation of the village forces villagers to zealously preserve their traditional living culture and to reflect the values of traditional settlement.

\subsection{Architectural comparison}

Typhoons are the most serious natural disaster for the island; thus the typology of all the main houses explicitly reflects this consideration. Nevertheless, different roof pitches, depths of pits, and interior chambers can be observed between the Yehyin and Langdau villages. The southwest and northeast monsoons are also considered for the roof design of the main houses. The roof pitch of all houses thus varies between $65^{\circ}$ and $70^{\circ}$. The length of the front roofs is always twice that of the back roofs due to the position of the ridge or the distributed proportion between the front and back chambers.

The depth of the pit is another important issue. The depths of the ground in Langdau are more obvious than those in Yehyin. In the studied case, the depth is $281 \mathrm{~cm}$ for Langdau and $170 \mathrm{~cm}$ for Yehyin. The heights of the main posts are 200 and $115 \mathrm{~cm}$, respectively. Figures 16 and 17 illustrate the different main houses of Yehyin and Langdau.

The land slope in Yehyin is $15 \%$ greater than the slope in Langdau. In order for the main house to obtain the same dimensions, it seems reasonable that the pit of the main house should be deeper in Yehyin. In fact, according to the field investigation, the result is on the contrary.

In terms of the geological data of Orchid Island, Yehyin is situated on the Talus Deposit, and Langdau is built on Alluvium (fluvial fan). Due to the higher permeability of land of the Talus Deposit, it is relatively easy to create the shallower pit of the main house in Yehyin. Alluvium contains coarse sand and gravel deposited by streams and rivers, which can provide an ideal storage medium for water. Consequently, people in Langdau are obliged to dig the pit deeper before constructing the main house. Figure 18 explains the different geological conditions between Yehyin and Langdau.

\subsection{Space transformation}

Figure 19 shows the different modes of transformation for Yehyin and for Langdau, respectively. Yehyin preserved the old settlement and added an extension. Developing in another direction, 

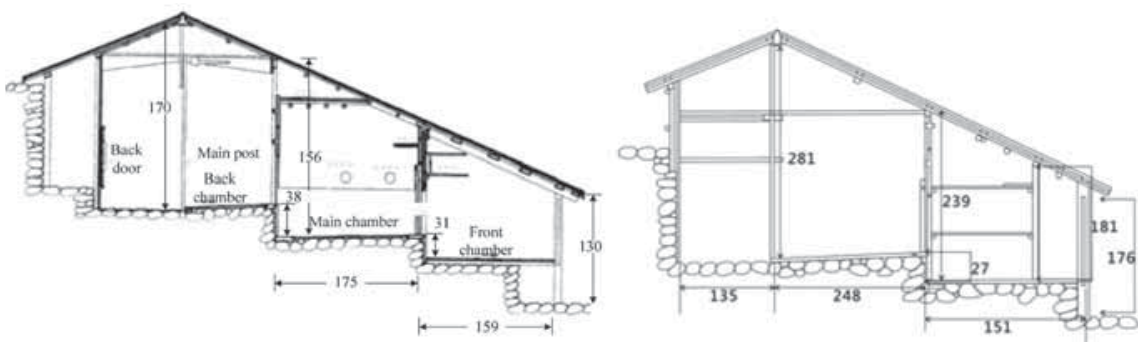

Figure 16: The profiles of a traditional main house in Yehyin (left-hand side) and Langdau (righthand side).
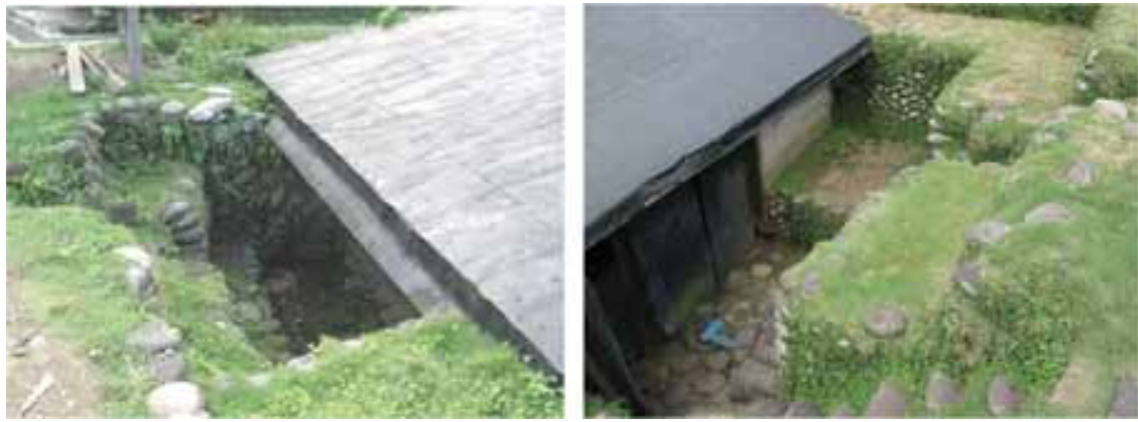

Figure 17: The different pit depths of a main house in Yehyin (left-hand side) and Langdau (righthand side).
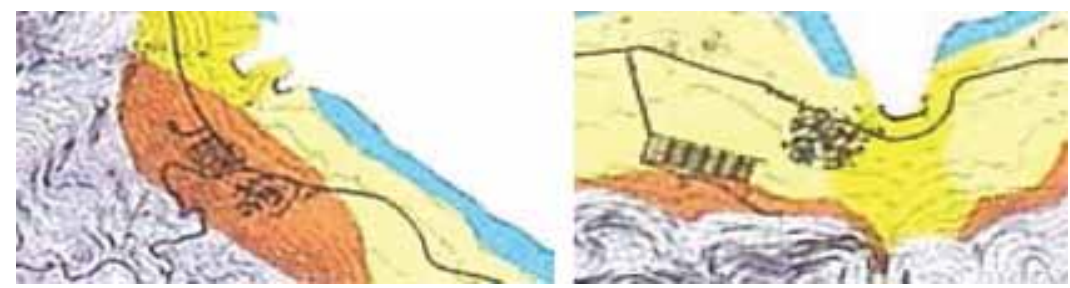

Figure 18: The geological conditions of Yehyin (left-hand side), which is situated on the Talus deposit and Langdau (right-hand side), which is situated on the Alluvium.

Langdau transformed and enlarged the village based on the original one. All farmlands and buffer zones, such as cemetery, shipyard, and desolate area, are thus reduced. However, the principle of village organization remains unchanged.

Although the Orchid Island residents actually live in a continually transforming environment, they remain conscious of their traditional living style. In order to maintain an extraordinary landscape that exudes the traditional texture and atmosphere of the village, the people restore or remodel their old dwellings using the subsidies provided by the government. The main construction material 
(wood) and erection method (handmade) should be respected in traditional ways. The appearance of the buildings should be retained without distinct changes.

Figure 20 presents two examples, which reflect the basic elements of a house plan that do not change the original characteristics of the building. The features such as the space order (corridorfront room-backroom-kitchen) and the arrangement are intact in remodeled houses. Figure 21 shows the traditional tattoos applied throughout the island, which echo the locals' attachment to their own culture.
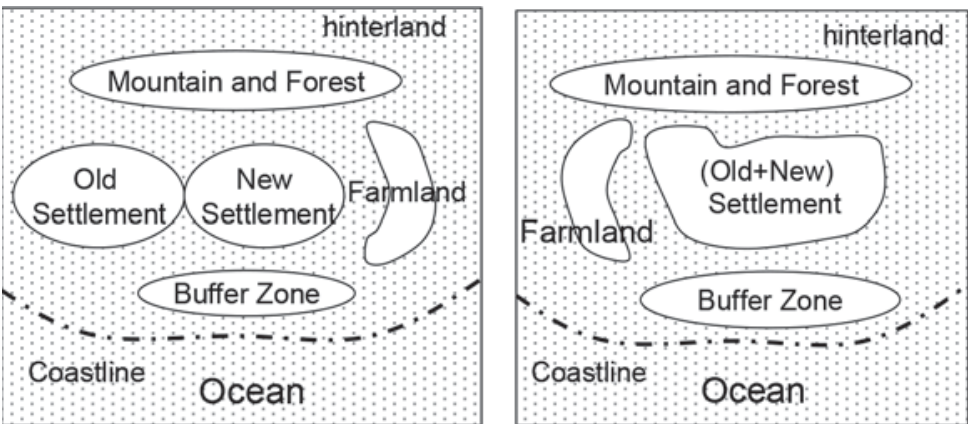

Figure 19: The modes of transition for Yehyin (left-hand side) and Langdau (right-hand side).
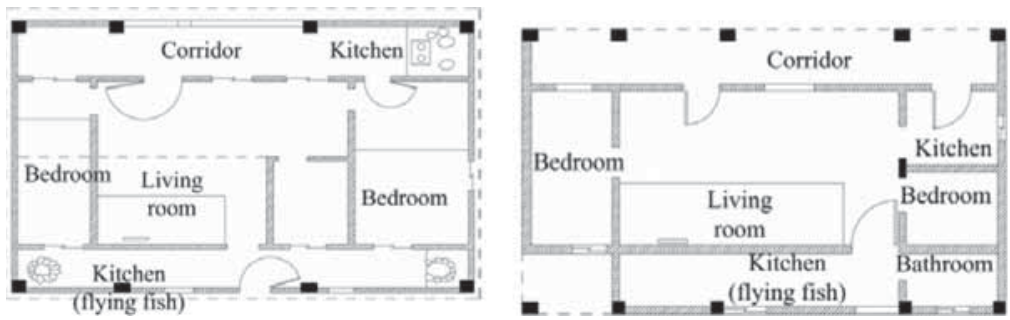

Figure 20: A remodeled house keeping traditional space elements [1].
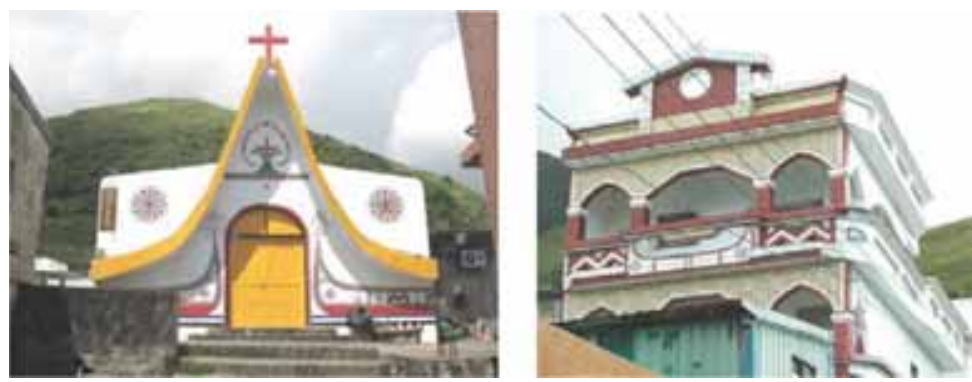

Figure 21: The community church (left-hand side) and a new modern dwelling (right-hand side). 


\section{CONCLUSION}

Unlike most conventional studies on the Orchid Island, this research focused mainly on natural circumstances rather than socio-economic issues. After comparing two case studies in the arrangement of the settlements and architectural composition, the environmental factors such as climate, geology, and topography have been identified as the main influencing factors for changes in the villages on Orchid Island.

Orchid Island is a unique human settlement for Taiwan, which, for the most part, remains historically intact and represents a precious human cultural landscape. The architectural composition on the island also demonstrates the concept of eco-design in primitive times. This should inspire new architectural developments on the island; more quantitative research and multi-disciplinary discussions on the Orchid Island are worth further investigation.

\section{REFERENCES}

[1] Kuo, S.-T. \& Chen, C.-J., The Sustainable Dwelling Development of Human Settlement on Orchid Island. Fourth International Conference on Sustainable Development and Planning, Cyprus, WIT Press, 2009.

[2] Chen, C.-J. \& Kuo, S.-T., The influencing factors of architectural composition and the arrangement of human settlement in Orchid Island. Design and Nature V, Comparing Design in Nature with Science and Engineering, Conference Proceedings, eds C.A. Brebbia \& A. Carpi, WIT Press: UK and University of Pisa: Italy, 2010.

[3] Suketarou, C., Aboriginal Dwellings in Taiwan (in Japanese), Tokyo, 1960.

[4] The History of my tribe (in Chinese), Government of Taitung County: Taitung, pp. 21 and 137, 2004.

[5] Huang, H., Yami's Living Culture and Change (in Chinese), Taipei, 1995.

This is a revised version of the paper published in WIT Transactions on Ecology and the Environment, Vol 138, ( 2010 WIT Press, www.witpress.com, ISSN 1743-3541 (on-line), doi: $10.2495 / \mathrm{DN} 100091$. 